\title{
Exploring Variability: New Brazilian Varieties SCS119 Rubi and SCS120 Onix for the Specialty Rices Market
}

\author{
Ester Wickert ${ }^{*}$, Moacir Antonio Schiocchet ${ }^{1}$, José Alberto Noldin', \\ Juliana Vieira Raimondi' ${ }^{2}$, Alexander de Andrade', Klaus Konrad Scheuermann', \\ Rubens Marschalek ${ }^{1}$, Gabriela Neves Martins' ${ }^{1}$, Eduardo Hickel ${ }^{1}$, \\ Domingos Savio Eberhardt ${ }^{1}$, Ronaldir Knoblauch ${ }^{1}$ \\ ${ }^{1}$ Epagri/Itajaí Experimental Station, Florianópolis, Brazil \\ ${ }^{2}$ UFSC/Plant Genetic Resources Department, Florianópolis, Brazil \\ Email: " esterwickert@epagri.sc.gov.br
}

Received 24 February 2014; revised 22 March 2014; accepted 20 April 2014

Copyright (C) 2014 by authors and Scientific Research Publishing Inc.

This work is licensed under the Creative Commons Attribution International License (CC BY). http://creativecommons.org/licenses/by/4.0/

\section{(c) (i) Open Access}

\begin{abstract}
"Specialty rices" is a common name for varieties that present uncommon grains with distinctive features as pericarp color, grain shape and size or aroma. Most of these rices are related to cultural traditions and ceremonies, but some have higher nutritionally value than white rice. Considering that today people are searching for foods that could help to improve and maintain health, specialty rices would also be considered in some way as functional food. As a specific market, the economic values of these grains are also higher than those of white rice. So, the new red rice variety SCS119 Rubi and the new black rice variety SCS120 Onix were developed in order to attend the specific and economically important specialty rices market, and should be consumed as a whole rice grain. Experimental tests performed with these varieties showed that they could be recommended to all rice-producing regions of Santa Catarina State, Brazil.
\end{abstract}

\section{Keywords}

Oryza sativa, Rice Breeding, Coloured Pericarp, Variety

\section{Introduction}

The Oryza L. genera belongs to the Poaceae (Gramineae) family and encompasses around 25 species, of which

${ }^{*}$ Corresponding author. 
23 are considered wild and only two are cultivated, i.e. O. sativa L. and O. glaberrima Steud [1]. O. sativa species is cultivated worldwide and O. glaberrima only in Africa.

On rice the commercial exploitation of a reduced genetic base and the prevalence of a small set of landraces in the breeding process has been the general approach for developing new varieties. However, if compared with other crop species the genetic diversity in world rice germplasm is quite large. Despite the richness of genetic resources, only a small proportion of the world rice germplasm collections have been used in breeding programs. As a consequence of the high genetic similarity found within several commercial rice germplasms around the world, their phenotypes present high resemblance.

Most rice that is grown and consumed throughout the world has white pericarp, but rice can also produce grains with brown, red, purple and black pericarp [2]. The color is visible when the grains are dehulled, but it can be removed by polishing to reveal the white endosperm.

Rices which are peculiar in one or more aspects are classified as specialty rices. They are different in some aspect related to grain pericarp colour, shape, size, amylose content and aroma [3]. As specialty rices their yields are usually lower than most commercial white rice varieties, but their economic value is higher. It is estimated that the market price for some rices with black pericarp can be up to ten times higher than that of the milled white rice varieties [2].

Red pericarp is ubiquitous among the wild ancestors of cultivated rice (O. rufipogon and O. nivara), and in some regions of the world red cultivars are preferred for their taste, texture, and ceremonial or medicinal value [4]. A similar tradition occurs in Brazil on Piancó Valley [5], where the red rice is widely preferred. Wild O. sativa genotype with red pericarp and seed shattering is a constant presence as a weedy in rice farmers' fields and is the most economically important weed and grain-quality problem faced by Brazilian rice producers.

The red pigment in rice grains is the proanthocyanidin, also called condensed tannins that are a branch of the anthocyanin pathway and share many of the same biosynthetic genes [6]. Proanthocyanidins have been shown to have important deterrent effects on pathogens and predators, so it is not surprising that spontaneous mutations that inhibit pigment production would be selected against in the wild [7]. Red pericarp is a genetic trait related to gene $\mathrm{Rd}$ on chromosome 1 with dominant effect.

Rices with black pericarp, usually called black rices are characterized by grains with dark purple pericarps with high levels of anthocyanins. During rice seed development, purple pigments of anthocyanin accumulate rapidly in the pericarp, resulting in the characteristic dark purple grains of black rice [8]. The black pericarp trait in rice is determined by the two genes $P b$ and $P p$ located on chromosome 1 and 4, respectively [8].

Originated from China, which is also the richest country in genetic resources, black rice is cultivated since ancient times. However, this colored rice was known in China as "forbidden rice" because common people were not allowed to eat it. Black rice was reserved only for the Emperor and his family and important country rulers. In modern times, black rices are found, cultivated and consumed mainly in Asian countries, associated to cultural traditions and ceremonies. Natural dark-colored food is known as "black food" and is very popular in China.

Regardless of the problems associated with red rice as a weed in rice fields, the red pigment is of interest for nutritional reasons. It is considered as a powerful antioxidant that has been demonstrated to reduce atherosclerotic plaque formation, a risk factor associated with cardiovascular disease [9].

On the same way, recent studies demonstrated that black rices could be easily considered as super food category because of its high levels of iron, essential amino acids, and fibers. Black rice can also be considered as a functional food because of being an important source of anthocyanin, a compound largely associated to antioxidant effects. Research results showed that phytochemicals such as phenolics and flavonoids compounds present in black rice grain are antioxidants associated with reduced risk of developing chronic diseases including cardiovascular disease, type-2 diabetes and some cancers [10]. These phytonutrients could also protect the body from cognitive decline and several other health disorders.

Rices developed for the specific needs of niche markets usually command a premium market price. This added-value benefits the rice producer. Although these specialty rices may not be grown on large acreage, there is an increasing demand in the market place for rices having novel cooking, flavor, processing, and appearance characteristics.

In fact that with growing prosperity, consumers are looking for better quality rice. Consumer interest in red and black rices represents a growing specialty market in the world, mainly associated as a functional food. This gave to these colored pericarp rices a differential market value, and could be an opportunity to help little rice farmers to enable their properties [3], as is the case of Santa Catarina State. 
It is also true that while much research has been done on common, high-yielding white rice varieties, far less attention has been paid to special kinds, even though they command higher prices. In this way, this work-as a part of the Rice Breeding Program of Epagri-has the objective of developing rice varieties with pigmented pericarp destined to the specialty rice grain market.

\section{Material and Methods}

\subsection{Pedigree and Breeding Method}

- SCS119 Rubi. Among years 1993 and 1999 many accessions of weedy red rice were collected from different cultivated white rice fields, constituting heterogeneous populations. These populations were then submitted to massal selection searching mainly for red long-shaped grains and without seed shattering. One of these improved populations still showing variations on plant architecture and life cycle was introduced on EEI (Itajaí Experimental Station-Estação Experimental de Itajaí) in 2004. Since that, this population (as a mixture of pure lines) was conducted according Pedigree Method with selection of single plants until 2008. During selection by Pedigree, every year many stabilized progenies were selected and evaluated for morphologic traits for the plant and the grain, and for productivity. During 2008 growing season some lines were selected and submitted to advanced trials and evaluated for resitance to diseases (mainly blast), iron toxicity and productivity. A flooding ocurred in this year and the trials were lost, being re-evaluated in 2009. The lines selected in 2009 formed the advanced trials conducted in EEI fields and were conducted under the same agricultural practices recommended by Epagri to the rice farmers. Among these lines, one was considered potential and received the name SC 608.

- SCS120 Onix. A hybridization of Epagri 107 X Riso Nero lineage was done in 1996 and the obtained seeds originated $F_{1}$ plants the following year. High genetic variability was displayed by $F_{2}$ plant populations, allowing phenotypic selection for agronomical interesting traits, as plant architecture, tillering, plant height, grain type, number of grain per panicle, and mainly pericarp color. Seeds from selected plants formed $\mathrm{F}_{3}$ generation. The same selection procedure was carried out to $\mathrm{F}_{7}$ generation (during 2007 growing season). From 2001 till 2004, the segregant populations were maintained in a dry and cold chamber and the selection of the populations restarted in 2005. A few lines were selected in 2007 and subsequently evaluated for yield, resistance to diseases, lodging and seed shattering. Because of segregation observed in some of these populations, two more selecting cycles were added (F6 and F7, years 2006 and 2007, respectively). Two lines were identified in 2007 growing season as promising and were named SC 606 and SC 607, respectively. These lines were evaluated in 2008 and 2009 for agronomical traits. Lineage SC 607 showed be better and was then conducted to assessments in larger plots $\left(60 \mathrm{~m}^{2}\right)$, in comparison with standard cultivars used in the region. At this point, uniformity, yield performance, grain pericarp colour, lodging resistance and blast resistance were evaluated.

\subsection{Performance at Field}

At this point, lines SC 607 and SC 608 were evaluated by its performance at field. The lines were phenotypically described for several traits (Table 1), according the descriptors recommended by rice culture by [11]. These productivity experiments were done at three locations with different soil and climate conditions representing the majority of edafoclimatic conditions of Santa Catarina State rice production areas. These experiments were done using rice varieties Epagri 108 and Epagri 109 with known performance as controls. These two controls are conventional white rice varieties and were used because today in Brazil there are not varieties of coloured pericarp that could be used in this way. These experiments were done during 2010 and 2011 growing seasons representing the VCU (Value for Cultivation and Use) trials during two years on three different locations on Santa Catarina State (Turvo, Araranguá and Itajaí) according recommendations of MAPA (Brazilian Ministry of Agriculture) for being registered. At this point, uniformity, yield performance, grain pericarp colour, lodging resistance and blast resistance were evaluated (characterizing the phenotypic description of agronomic traits). Based on the productivity performance at these locations allied with its desirable agronomic traits, these two lines were considered able to be released as varieties.

\subsection{Line Identification}

At the end of these performance tests, line SC 607 received the name SCS120 Onix remembering its black pericarp. And the SC 608 line was identified as SCS119 Rubi, also in allusion of its red pericarp. The two varieties 
were released and recommended in 2013 as new rice varieties for specialty rice market.

\subsection{Grain Characteristics}

During the final experimental field trials, grain sample of each line were submitted to evaluations as size and milling performance. Size measures were done using an automatic caliper rule. Milling tests were done using laboratory mills and proportion of broken and whole grains were done using percentage.

\subsection{Chemical Composition}

A sample of SCS119 Rubi and SCS120 Onix were also submitted to analysis on order to determine its chemical composition as protein, lipids, carbohydrate, fiber, anthocyanins and phenolic compounds (Table 2). This was done at Department of Pharmaceutical Sciences of Sao Paulo University using previously described methodologies [12]-[14].

Table 1. Agronomic and phenotypic characteristics of SCS119 Rubi and SCS120 Onix, measured in the VCU trials (Itajaí, Araranguá and Turvo) in 2010 and 2011 growing season.

\begin{tabular}{ccc}
\hline Plant trait & SCS119 Rubi & SCS120 Onix \\
\hline Leaf color & Green & Green \\
Leaf pubescence & Medium & Medium \\
Flag leaf angle & Upright & Upright \\
Tillering & Medium & Medium \\
Cycle to maturity & 125 days & 125 days \\
Plant height & 105 cm & 107 cm \\
Lodging & Moderate & Moderate \\
Resistance to blast & Moderate & Moderate \\
Iron toxicity tolerance & Moderate & Moderate \\
Pericarp color & Red & Black \\
Glumella color & Golden & Golden \\
Apex color at maturity & Yellow & Brown \\
Awns & Absent & Absent \\
Shattering & Intermediate & Intermediate \\
Weight (g/1000 seeds) & 26.5 & 19.5 \\
\hline
\end{tabular}

Table 2. Centesimal composition of Rice varieties SCS119 Rubi, SCS120 Onix and White Rice Epagri 109 on its whole form (without polishing).

\begin{tabular}{cccc}
\hline Composition & SCS120 Onix & SCS119 Rubi & Epagri 109 \\
\hline Proteins (g/100g of rice) & 11.2 & 9.0 & 8.7 \\
Lipids (g/100g of rice) & 3.6 & 3.0 & 80 \\
Carbohydrates (g/100g of rice) & 78 & 1.6 & 1.6 \\
Minerals (g/100g of rice) & 1.7 & 1.0 & 0.5 \\
Soluble alimentar fiber (g/100g of rice) & 1.2 & 5.4 & 3.2 \\
Insoluble alimentar fiber (g/100g of rice) & 4.4 & 0.2 & 280 \\
Anthocyanins (flavonoids) & 2.5 & 260 & 826 \\
Total phenolic acids (ug/g rice) & 750 & 3400 & \\
\hline
\end{tabular}




\section{Results}

\subsection{Performance of SCS119 Rubi and SCS120 Onix at Field}

SCS119 Rubi presents a modern plant type with medium cycle (125 days to maturity) and erect and hairy leaves (Figure 1 and Figure 2). The cultivar presents good resistance to lodging, a trait considered essential for the pre-germinated cultivation system used in Santa Catarina and Rio Grande do Sul States. It has also low seed
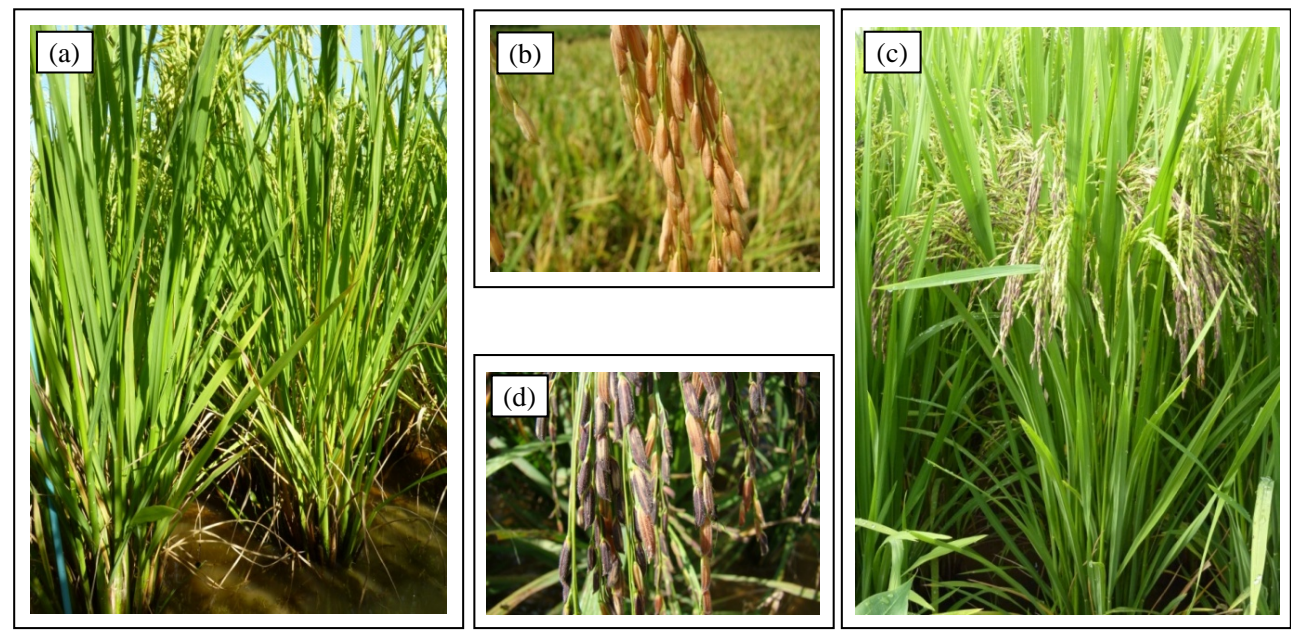

Figure 1. Morphological traits of varieties SCS119 Rubi (a) and aspect of the grain (b), and SCS120 Onix (c) with aspects of the grain (d) as observed in field.
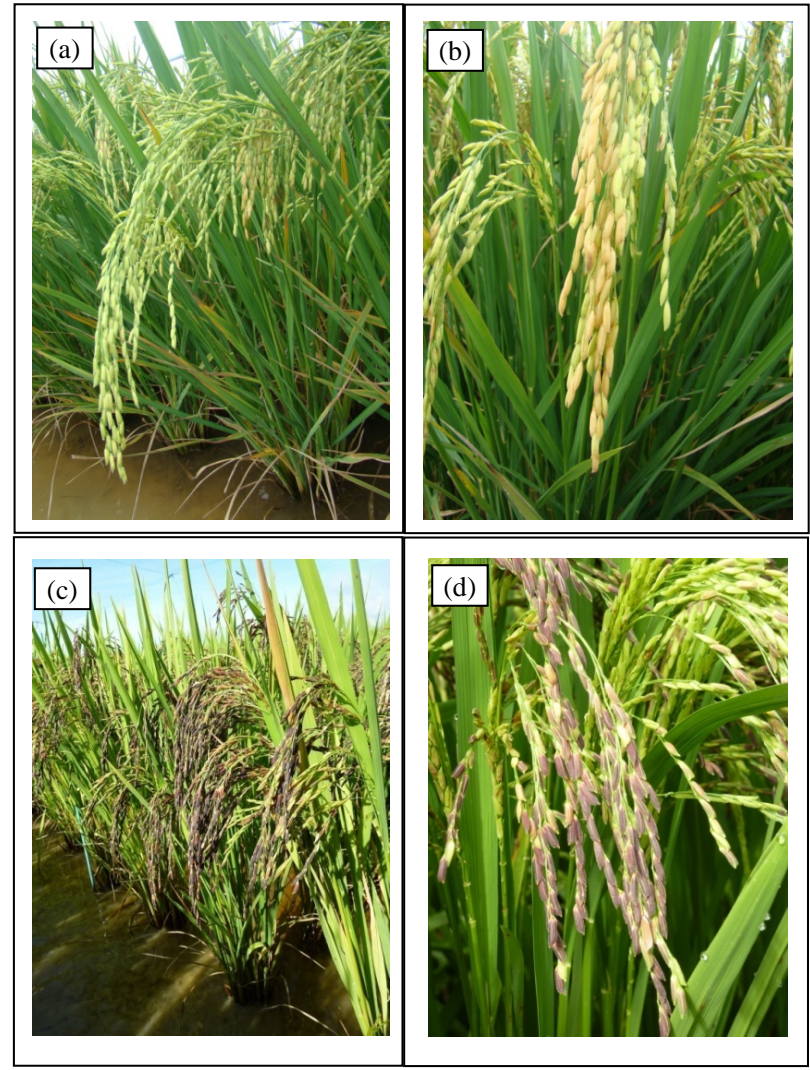

Figure 2. Some aspects of the varieties SCS119 Rubi and SCS120 Onix as observed in field. 
shattering and moderate susceptibility to iron toxicity and blast. SCS119 Rubi presented good yield in regional trials (Itajaí, Araranguá, and Turvo) with an average of $7700 \mathrm{~kg} \cdot \mathrm{ha}^{-1}$ (Table 3). Despite SCS119 Rubi showed a little low productivity when compared to the controls, the red pericarp colour should determine its market value.

SCS120 Onix has also a modern plant type with medium life cycle (125 days to maturity) with erect and hairy leaves. The cultivar presents good resistance to lodging (Figure 1 and Figure 2). It has also medium tillering capacity, intermediate seed shattering and moderate susceptibility to iron toxicity and blast. SCS120 Onix could also presents few sterily spikelets, but presented an adequate yield in the regional trials (Itajaí, Araranguá, and Turvo) with an average of $5468 \mathrm{~kg} \cdot \mathrm{ha}^{-1}$ (Table 3) considering that high yield was not a decisive factor for this variety.

\subsection{Grain Characteristics of SCS119 Rubi and SCS120 Onix}

The grains of the two varieties should be consumed as a whole grain and are also recommended to be parboiled, preserving his characteristics as colour and taste. Parboililed grains showed uniformity and enhancement on pericarp color.

Sensorial test showed that SCS119 Rubi should be suitable for the specialty rices market, presenting longshaped grains with red coloured pericarp, and good aroma (Figure 3). The milling total yield for this rice is considered appropriate, with value of $77.4 \%$ and $73.0 \%$ of whole grain (Table 4 ).

SCS120 Onix has also long-shaped grains with highly black pericarp, and good aroma, referred as a nut-like aroma (Figure 3). The total milling yield for SCS120 Onix is $64.6 \%$ with $56.5 \%$ of whole grain (Table 4).

\subsection{Chemical Composition}

The varieties SCS119 Rubi and SCS120 Onix presented similar values of Protein, lipids, carbohydrates, minerals and fibers when compared to white rice Epagri 109. However, they showed higher values of anthocyanins and phenolic compounds when compared to white rice varieties. Red pericarp variety SCS119 Rubi showed almost three more times phenolic compounds than white pericarp Epagri 109 and black pericarp SCS120 Onix showed almost five more times.

\section{Discussion}

The origin of pigmented rices is as old as rice itself, and they are involved in different oriental myths, with red rices occupying a special position since immemorial times in India [14]. It is also a fact that the first domesticated rice had a pigmented pericarp [1] [2].

Table 3. Average grain yield $\left(\mathrm{kg} \cdot \mathrm{ha}^{-1}\right.$ ) of SCS119 Rubi, SCS120 Onix, Epagri 108 and Epagri 109, in the VCU trials (Itajaí, Turvo and Araranguá) during 2010 and 2011 growing season.

\begin{tabular}{cccccccc}
\hline & \multicolumn{3}{c}{ Itajaí } & \multicolumn{3}{c}{ Turvo } & \multicolumn{2}{c}{ Araranguá } \\
\cline { 2 - 7 } Varieties & $\mathbf{2 0 1 0}$ & $\mathbf{2 0 1 1}$ & $\mathbf{2 0 1 0}$ & $\mathbf{2 0 1 1}$ & $\mathbf{2 0 1 0}$ & $\mathbf{2 0 1 1}$ \\
\cline { 2 - 7 } & & & & $\mathbf{k g}^{-h^{-1}}$ & & & 7250 \\
SCS119 Rubi & 6500 & 9217 & 7500 & 9500 & 6233 & 4300 \\
SCS120 Onix & 5030 & 6156 & 5589 & 6100 & 5633 & 8830 \\
Epagri 108 & 8090 & 8693 & 9517 & 9280 & 9733 & 10,180 \\
Epagri 109 & 9540 & 9856 & 8456 & 11,460 & 9467 & \\
\hline
\end{tabular}

Table 4. Physical and chemical grain characteristics of rice cultivar SCS119 Rubi.

\begin{tabular}{|c|c|c|c|c|c|c|c|c|c|c|}
\hline & \multicolumn{3}{|c|}{ Milling yield (\%) } & \multirow{2}{*}{$\mathrm{AC}$} & \multirow{2}{*}{$\mathrm{GT}$} & \multicolumn{4}{|c|}{ Grain size (mm) } & \multirow{2}{*}{ Class } \\
\hline & Total & Whole & Broken & & & $\mathrm{L}$ & W & $\mathrm{T}$ & $\mathrm{L} / \mathrm{W}$ & \\
\hline SCS119 Rubi & 77.4 & 73.0 & 4.4 & 22.5 & I & 7.38 & 2.33 & 1.86 & 3.17 & Long-thin \\
\hline SCS120 Onix & 64.6 & 56.5 & 7.8 & 20.5 & I & 7.41 & 1.93 & 1.59 & 3.84 & Long-thin \\
\hline
\end{tabular}

Total: Percentage of total grain milled; Whole: Percentage of whole grain; Broken: Percentage of broken grain; AC: Percentage of amylose content; GT: Gelatinization temperature (I: intermediate); L: Grain length; W: Grain width; T: Thickness and L/W: Length width ratio. 

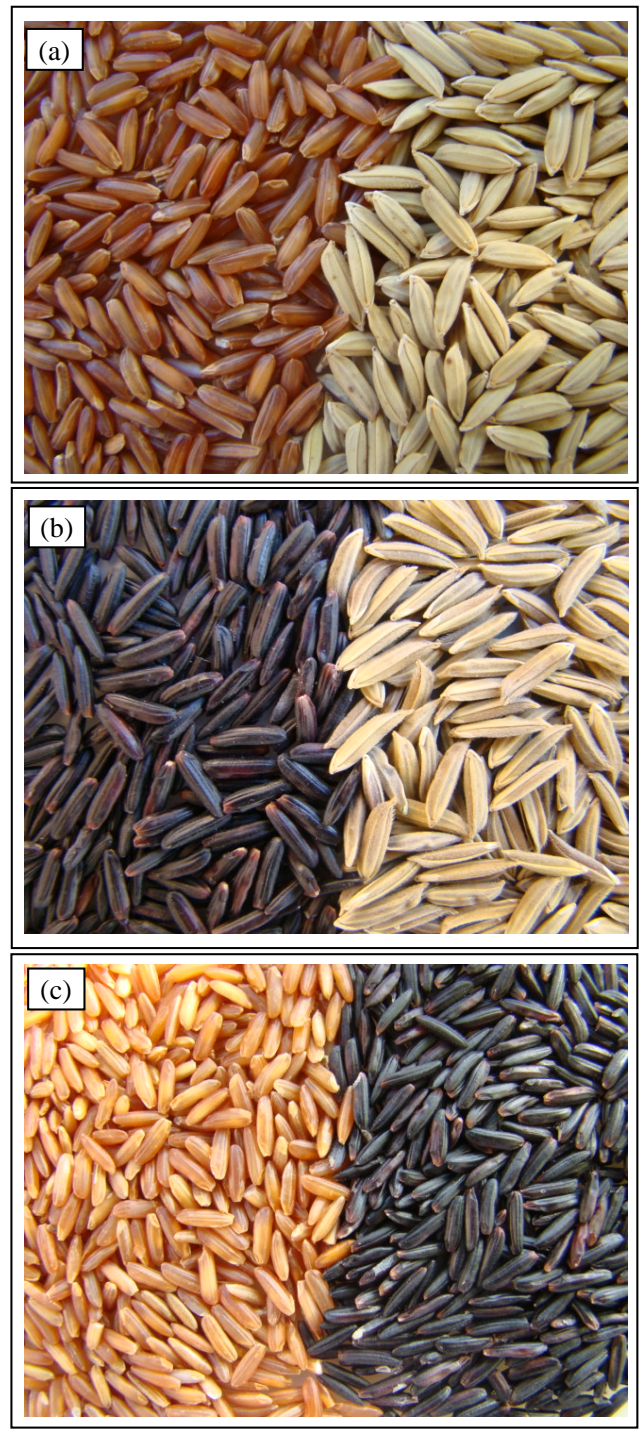

Figure 3. Morphological aspect of whole and husked grain of SCS119 Rubi (a), SCS120 Onix (b) and the contrast between the two varieties (c).

The development of varieties of colored pericarp by Epagri Rice Project is part of an initiative to offer a portfolio of specialty rices covering varieties of red and black pericarp, aromatic and glutinous types destined to specific market niches. Products associated to this special niches, have also a higher market value when compared to the traditional products. This also happens with rice, with specialty rices owing in some case more than ten times the value of the traditional white rice.

These niche markets encompasses those related to some traditional foods like the Italian "risotto", the Spanish "paella", the oriental aromatic Thailand's food and the Japanese "sushi", and the Chinese traditional red rice cake, that today are spread around the world [15]. Because of Italian immigration to Brazil on the past centuries, there is a growing market associated mainly to risotto.

But probably the specialty rice most consumed in Brazil today is the rice with red pericarp. This food has a strong cultural importance and there are many different rice land races with red pericarp. But as far as we know, SCS119 Rubi is the first variety developed and recommended by research for cultivation. As the SCS120 Onix is also the firt black pericarp variety completely developed and released in Brazil, despite the fact that one black variety was firstly introduced, adapted and released by IAC (Campinas Agronomic Institute/Sao Paulo State) in 2001, called IAC 600. This variety presents short black grains and has its growing place is almost restricted to 
Vale da Ribeira areas in Brazilian Sao Paulo State.

So, the two coloured pericarp rice varieties developed by Epagri are recommended for cultivation in all areas of Santa Catarina State and experimental trials done in rice growing areas of Rio Grande do Sul, Goias and Piauí States revealed that the two varieties could also be cultivated in this areas with excellent productivities.

One reason of the differential market value for these two varieties is that these two coloured varieties could also be classified as nutraceutical or functional food, mainly because of its phenolic compounds, that are known for its ability as antioxidants. It is largely exposed by the midia that people are eating lots of industrialized food that causes several problems along the time. Another reason is that these varieties are consumed as a whole (integral) grain, increasing the highly desirable fiber diary income. So, many people are interested in do things for wellness and lifelong health. Nutrient-rich food is an essential step for this objective.

Brazil consumes rice mainly as polished or parboiled and prefers grains with long shaped and white pericarp. But the interest on different rices is growing, as it is happening also for other foods, like beans, coffee and olive oil, as some examples. Santa Catarina State has a peculiar agricultural structure, composed mainly by farmers cultivating small areas (1 - 10 hectares) with the owner and his family as the principal labor arms. So, cultures with distinctive and aggregated market value are very interesting in order to make these little areas economically viable, avoiding little farmers to leave its properties and search for job in industrial or commercial areas.

The development and release of these specialty rice varieties also shows an example of the potentiality of exploring the genetic diversity in natural resources for economical purposes. Assuming that it is easy to protect known things, the use of genetic resources in order to develop special products for many different purposes (food industry, pharmaceuticals and others) could help to know and conserve genetic resources.

\section{Pedigree Seed Maintenance and Distribution}

Registration process of these new cultivars in the Ministry of Agriculture, Livestock and Food Supply (Ministério da Agricultura Pecuária e Abastecimento-MAPA) is an important step for seed production and commercialization in Brazil. Registration assures the genetic identity and varietal quality for breeding programs. Additionally, cultivar protection guarantees royalties to private and public breeding and seed companies, which can use these resources to continue their research and development projects [16].

So, the SCS119 Rubi variety is registered by the National Cultivar Registry (Registro Nacional de Cultivares RNC) of the Ministry of Agriculture, Livestock and Supply under the number 30233, in Brazil. SCS120 Onix is registered by the National Cultivar Registry under protection number 20130079. The genetic seed stock is kept by Epagri, Itajaí Experiment Station, located at Rodovia AntOnio Heil, n.6800, Itaipava, P.O. Box 277, CEP 88301-970, Itajaí, SC, Brazil.

\section{Conclusion}

The two new rice varieties SCS119 Rubi and SCS120 Onix were considered suitable to be cultivated on rice areas of Santa Catarina State and would be an alternative in order to help little farmers be economically viable. So, we believe that these new rice varieties can exemplify the use of natural genetic diversity of rice in order to improve economically the income of small farmers and help in the efforts of protecting and conserving genetic diversity.

\section{Acknowledgements}

To the farmers who allowed conducting experiments on their properties, as well as the technicians and extensionists who contributed to the development of this new technology, our recognition. To Embrapa Arroz e Feijão (CNPAF), for the chemical analysis of the grains. We are also grate do Dr. Ursula Lanfer Marquez and Dr. Isabel Louro Massareto of São Paulo University for the chemical analysis. Also to FAPESC (Fundação de Amparo a Pesquisa e Inovação do Estado de Santa Catarina) and CNPq (Conselho Nacional de Desenvolvimento Científico e Tecnológico) that financially supported the research.

\section{References}

[1] Khush G.S. (1997) Origin, Dispersal, Cultivation and Variation of Rice. Plant Molecular Biology, 35, 25-34. http://dx.doi.org/10.1023/A:1005810616885 
[2] Chaudhary, D.V.T. and Duffy, R. (2001) Specialty Rices of the World: Breeding, Production, and Marketing. FAO Science Publishers, Rome, 358p.

[3] Magalhães Jr., A.M., Franco, D.F., Fagundes, P.R.R., Morais, O.P., Pereira, J.A., Cordeiro, A.C.C., Wickert, E., Moura Neto, F.P. and Severo, A.C.M. (2012) Indicação de Tipos Especiais de Arroz para Diversificação de Cultivo. Editora Embrapa, Pelotas, 8 p. (Circular Técnica, 133) http://www.infoteca.cnptia.embrapa.br/handle/doc/954892

[4] Sweeney, M.T., Thomson, M.J., Pfeil, B.E. and CcCouch, S. (2006) Caught Red-Handed: Rc Encodes a Basic HelixLoop-Helix Protein Conditioning Red Pericarp in Rice. The Plant Cell, 18, 283-294. http://dx.doi.org/10.1105/tpc.105.038430

[5] Almeida, J.A.P. (2004) O arroz vermelho cultivado no Brasil. Editora Embrapa: Embrapa Meio Norte, Teresina, 90p.

[6] Winkel-Shirley, B. (2001) Flavonoid Biosynthesis. A Colorful Model for Genetics, Biochemistry, Cell Biology, and Biotechnology. Plant Physiology, 126, 485-493. http://dx.doi.org/10.1104/pp.126.2.485

[7] Shirley, B. (1998) Flavonoids in Seeds and Grains: Physiological Function, Agronomic Importance and the Genetics of Biosynthesis. Seed Science Research, 8, 415-422. http://dx.doi.org/10.1017/S0960258500004372

[8] Rahman, M.M., Lee, K.E., Lee, E.S., Matin, M.N., Lee, D.S., Yun, J.S., Kim, B.J. and Kang, S.G. (2013) The Genetic Constitutions of Complementary Genes Pp and Pb Determine the Purple Color Variation in Pericarps with Cyanidin-3O-glucoside Depositions in Black Rice. Journal of Plant Biology, 56, 24-31. http://dx.doi.org/10.1007/s12374-012-0043-9

[9] Ling, W.H., Cheng, Q.X., Ma, J. and Wang, T. (2001) Red and Black Rice Decrease Atherosclerotic Plaque Formation and Increase Antioxidant Status in Rabbits. Journal of Nutrition, 131, 1421-1426. http://jn.nutrition.org/content/131/5/1421.full.pdf+html

[10] Bioversity International, IRRI and WARDA (2007) Descriptors for Wild and Cultivated Rice (Oryza spp.). Bioversity International, Rome, Italy; International Rice Research Institute, Los Baños, Philippines; WARDA, Africa Rice Center, Cotonou, Benin, 63p. http://www.bioversityinternational.org/uploads/tx_news/Rice_232.pdf

[11] Shao, Y., Jin, L., Zhang, G., Lu, Y., Shen, Y. and Bao, J. (2011) Association Mapping of Grain Color, Phenolic Content, Flavonoid Content and Antioxidant Capacity in Dehulled Rice. Theoretical and Applied Genetics, 122, 1005-1016. http://dx.doi.org/10.1007/s00122-010-1505-4

[12] Singleton, V.L., Orthofer, R. and Lamuela-Raventós, R.M. (1999) Analysis of Total Phenols and Other Oxidation Substrates and Antioxidants by Means of Folin-Ciocalteu Reagent. Methods in Enzymology, 299, 152-178. http://dx.doi.org/10.1016/S0076-6879(99)99017-1

[13] Zhou, Z., Robards, K., Helliwell, S. and Blanchard, C. (2004) The Distribution of Phenolic Acids in Rice. Food Chemistry, 87, 401-406. http://dx.doi.org/10.1016/j.foodchem.2003.12.015

[14] Tian, S., Nakamura, K., Cui, T. and Kayahara, H. (2005) High-Performance Liquid Chromatographic Determination of Phenolic Compounds in Rice. Journal of Chromatography A, 1063, 121-128. http://dx.doi.org/10.1016/j.chroma.2004.11.075

[15] Ahuja, U., Ahuja, S.C., Chaudhary, N. and Thakrar, R. (2007) Red Rices-Past, Present, and Future. Asian Agri-History, 11, 291-304. http://asianagrihistory.org/articles/Red-Rices-Uma-Ahuja.pdf

[16] Carvalho, S.I.C., Bianchetti, L.B. and Reifschneider, F.J.B. (2009) Registro e proteção de cultivares pelo setor público: A experiência do programa de melhoramento de Capsicum da Embrapa Hortaliças. Horticultura Brasileira, 27, 135138. http://dx.doi.org/10.1590/S0102-05362009000200002 